\title{
A comparison of the ultrastructure of spray-frozen and freeze-etched or freeze-dried bull and boar spermatozoa with that after chemical fixation
}

\author{
W. Pfaller, E. Rovan and H. Mairbäurl \\ Institute of Physiology, University of Innsbruck, and Institute of Zoology, \\ University of Salzburg, Austria
}

\begin{abstract}
Summary. The ultrastructure of bull and boar spermatozoa was investigated following different cryopreparation methods and chemical fixation. Spray-freezing was used for cryofixation in both freeze-etching and freeze-drying studies. Freeze-etching of boar spermatozoa revealed that the arrangement of the postnuclear striations differed from that in the bull. Freeze-drying gave excellent results for structural preservation, which were equal to those of chemical fixation. Some structural details not visible in chemically fixed cells were detected in freeze-dried and vacuum-embedded bull and boar spermatozoa, e.g. the arrangement of the lamellar nuclear contents, known from freezefractures, and a fine lamellar structure of the acrosomal contents. Cryofixation by spray-freezing combined with freeze-drying makes any contact of the cells with fixatives, buffer solutions and dehydration media unnecessary, and potentially provides all the advantages of ultrathin sectioning required for histochemical studies.
\end{abstract}

\section{Introduction}

The fine structure of spermatozoa has been investigated primarily after chemical fixation (Blom \& Birch-Anderson, 1960, 1965; Saacke \& Almquist, 1964a, b; Hancock, 1966; Nicander \& Bane, 1966; Fawcett, 1970) or freeze-etching (Koehler, 1966, 1970). In both techniques cellular components are variably altered by the fixatives, the dehydration media or the cryoprotective agents. The technique of freeze-drying has been applied to the preparation of specimens for electron microscopy, but the results have been unsatisfactory (Gersh \& Stephenson, 1954; Sjöstrand \& Baker, 1958; Hanzon \& Hermodson, 1960). Structural preservation was poor because of ice-crystal formation during the quick freezing.

The spray-freezing method developed by Bachmann and his colleagues (Bachmann \& Schmitt, 1971 ; Plattner, Fischer, Schmitt \& Bachmann, 1972; Plattner, Schmitt-Fumian \& Bachmann, 1973) has opened a new door in the investigation of biological structure. This technique provides rapid cooling rates and prevents the formation of ice crystals, thus stabilizing the natural cell structure and minimizing damage.

Although freeze-etching is the method of choice to judge the ultrastructural preservation obtained by cryofixation with the spray-freezing method, it is important for many types of structural studies to combine the fixation quality provided by spray-freezing with the advantages of the conventional thinsectioning technique. We felt that a useful approach to this problem would be to process sprayfrozen cells by freeze-drying and vacuum-embedding to prevent any contact of the specimen with aqueous or organic solutions (fixatives, buffer solutions, dehydrating media), which might elute or transform cellular materials between 'fixation' and resin embedding.

\section{Materials and Methods}

Freshly collected bull and boar semen was concentrated by gentle centrifugation for $10 \mathrm{~min}$ at room temperature. The supernatant was removed and the concentrated spermatozoa were suspended and 


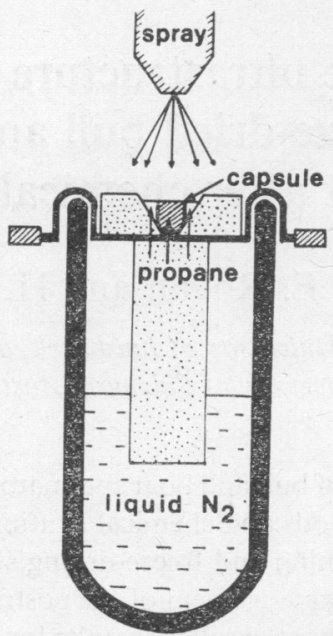

Text-fig. 1. Spray-freezing device with the gelatine capsule submerged in liquid propane.

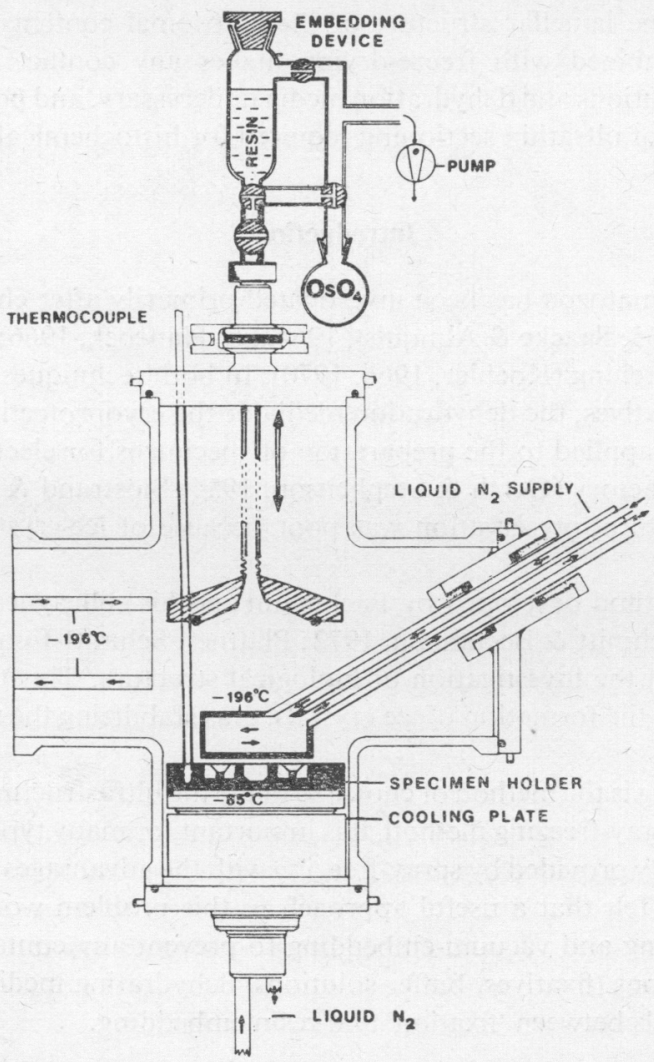

Text-fig. 2. Schematic drawing of the vacuum chamber used for freeze drying. The specimen holder containing the gelatine capsules is sealed by a fitting with a special flange when freeze-drying is finished and the movable cold finger retracted. After flooding the outer vacuum chamber the specimen holder can be moved out and the dried specimens will be infiltrated by previously de-gassed epoxy-resin or treated by $\mathrm{OsO}_{4}$ vapours before infiltration. 
sprayed into a gelatine capsule located in liquid propane (Bachmann \& Schmitt, 1971) cooled by liquid nitrogen (Text-fig. 1). The spraying pressure was adjusted so that maximum motility of the spermatozoa after spraying was guaranteed. The capsules were then quickly transferred into liquid nitrogen where they could be stored until further processing.

Some of the spray-frozen spermatozoa were processed for freeze-etching in a BALZERS BAF 301 as described by Bachmann \& Schmitt (1971).

For freeze-drying the capsules containing the spray-frozen cells were transferred into fittings on a thermostat-controlled copper specimen holder $\left(-85^{\circ} \mathrm{C}\right)$ within a high vacuum chamber (Text-fig. 2$)$. A specially designed movable cold finger supplied with liquid nitrogen was then placed as close as possible to the specimens to provide a maximum sublimation rate for ice at a final pressure of $10^{-6}$ Torr within the vacuum chamber. The period required for drying under these conditions was $60 \mathrm{hr}$. The specimens were than warmed at a continuous rate to room temperature and vacuum-infiltrated with previously de-gassed epoxy resin (Durcupan ACM, Fluka, Switzerland). The principle of the freeze-drying apparatus used was also described by Müller (1957) and by Stirling \& Kinter (1967). The differences are in the construction of our movable cold-finger and its position during drying. The steradiant between specimens and cold finger is much greater and the distance much shorter so that a maximum sublimation of ice and shorter drying times are guaranteed. In contrast to all previously described apparatus, any contact of dried specimen with the environmental atmosphere can be avoided. Some of the freeze-dried specimens were fixed by $\mathrm{OsO}_{4}$ vapours (Gersh, Veraga \& Rossi, 1960) before vacuum infiltration with resin (Text-fig. 2).

A portion of the freshly collected ejaculate was chemically fixed in $1 \%$ glutaraldehyde buffered by $0.175 \mathrm{~mol}$ sodium cacodylate/litre ( $\mathrm{pH} 7 \cdot 35$, osmolarity $440 \mathrm{mosmol} / \mathrm{litre}$ ) which was found to give better results than iso-osmotic fixatives (Jones, 1970). Specimens were postfixed in $1 \% \mathrm{OsO}_{4}$ (buffered as before), dehydrated in acetone and embedded in Durcupan ACM (Fluka).

After these preparation steps the specimens were polymerized at $60^{\circ} \mathrm{C}$. Ultrathin sections were either left unstained or stained with uranyl acetate ( $5 \%$ unbuffered solution) followed by lead citrate (Reynolds, 1963). The sections were examined with a JEOL 100C or a Philips 300 electron microscope.

\section{Results}

\section{Spray-frozen and freeze-etched spermatozoa}

The frozen droplets contained an average of 1-3 cells and showed no ice-crystal formation. In general the appearance after freeze-etching substantiated the earlier findings of Plattner (1971). The plasma membrane of the sperm head was characterized by a homogeneous array of 50-70 $\AA$ particles, sometimes arranged in a highly ordered crystalline pattern and large particles (200 $\AA$ ) of irregular shape and distribution (Pl. 1, Fig. 2). 'Striations' were clearly visible on the posterior parts of the head membrane (Koehler, 1965, 1970; Plattner, 1971), but there were striking differences between bull and boar spermatozoa in the appearance, extension and amount of 'striation' (P1. 1, Figs 2 and 3). In the boar, the striations are confined to the head-neck junction and consist of diagonal strips at an angle of $40^{\circ}$ to the longitudinal axis of the striation ridges (PI. 1, Fig. 3). In bull spermatozoa, the striation ridges are parallel and the spacing between the ridges is of the same dimension as their width (350$500 \AA$ ). Particles of about $200 \AA$, similar to those of the head membrane, are sometimes superimposed on the striations.

No differences in the structure of the acrosomal membranes were observed for bull and boar spermatozoa. The 'cobble-stone' pattern of the inner acrosomal membrane was clearly seen (Pl. 1, Fig. 4) and easy to differentiate from the adjacent nuclear membrane (Plattner, 1971). The nuclear content was characterized by a lamellar aray (Pl. 1, Fig. 4) which can also be seen sometimes in chemically fixed spermatozoa (Koehler, 1970). The tail membranes appeared similar to those of the head region, while the plasma membrane of the middle piece showed a relief corresponding to the underlying mitochondrial chain (PI. 1, Fig. 5). Dissociation of the plasma membrane of freezeetched spermatozoa was never found when all the parameters of the spray-freezing, and especially the spray pressure, were carefully controlled. 
Freeze-dried and vacuum-embedded spermatozoa compared with chemically fixed cells

The membranes of unfixed and unstained freeze-dried spermatozoa were distinguishable but rather 'hazy' in comparison with those of chemically fixed spermatozoa (Pl. 2, Figs 6 and 8). Staining with uranyl acetate and lead citrate produced membrane distinctions (Pl. 2, Fig. 7) equivalent to those found after optimal chemical fixation with $\mathrm{OsO}_{4}$ (Pl. 2, Fig. 8). The continuity of the cytoplasmic membrane was well preserved and there were no interruptions, outfoldings or dissociations that are often visible after chemical fixation (P1. 2, Figs 8 and 10). The outer acrosomal membrane of freezedried spermatozoa was preserved as well as the plasma membrane (Pl. 2, Fig. 9), but fine lamellar structures not detected after chemical fixation were sometimes seen within the acrosome (Pl.3, Fig. 11). Lamellar structures were seen in the nuclei of freeze-dried spermatozoa but only rarely in those of chemically fixed cells.

The greatest differences in the results of the two techniques were observed in the flagellar complex. The mitochondrial matrix was more electron-dense in freeze-dried specimens (Pl. 3, Figs 13 and 15), and the doublet microtubule nature of the outer nine microtubules could not be distinguished (Pl. 3, Figs 15 and 16). The cytoplasmic membranes and the mitochondrial membranes look similar to those observed with chemical fixation.

\section{EXPLANATION OF PLATES}

Sections of bull and boar spermatozoa prepared by different techniques.

Abbreviations: N, nucleus; A, acrosome; SA, subacrosomal space; C, cytoplasm; STR, 'striation'; HN3, head-neck junction; PERF, perforatorium; PM, plasma membrane; OAM, outer acrosomal membrane; NM, nuclear membrane; LAC, lamellar acrosomal content; IAM, inner acrosomal membrane; LNC, lamellar nuclear content; PMO, outer side of plasma membrane; PMI, inner side of plasma membrane; MT, microtubules; Mi, mitochondria; ODF, outer dense fibres.

\section{Plate 1}

Fig. 1. Cross-section through a freeze-dried unosmicated but stained (uranyl acetate followed by lead citrate) boar spermatozoon.

Fig. 2. Posterior part of a freeze-etched bull sperm head; note the highly ordered crystalline pattern of the bull sperm head plasma membrane (arrows).

Fig. 3. Inside view of the plasma membrane of the posterior part of a freeze-etched boar sperm head demonstrating the 'striations'.

Fig. 4. Freeze-etched bull sperm head.

Fig. 5. Middle piece plasma membrane showing the protrusions (PT) caused by the underlying mitochondrial chain.

Plate 2

Fig. 6. Longitudinally sectioned bull spermatozoon. No osmication, no staining with uranyl acetate and lead citrate. Note the 'hazy' appearance of the membranes.

Fig. 7. Same sectional position as shown in Fig. 6, but the spermatozoon was stained with uranyl acetate and lead citrate.

Fig. 8. Longitudinal section of a chemically fixed bull spermatozoon. The lamellar content of the nucleus and the acrosome is not visible. Furthermore the plasma membrane is often interrupted (INT) and dissociated from the underlying outer acrosomal membrane (DIS).

Fig. 9. Higher magnification of the sperm rostrum of the specimen shown in Fig. 7 (freeze-dried and stained by uranyl acetate and lead citrate).

Fig. 10. The same position as shown in Fig. 9 but from a chemically fixed cell.

Plate 3

Figs 11, 13 and 15. Sections of spermatozoa freeze-dried and stained with uranyl acetate and lead citrate. Fig. 11, boar; Figs 13 and 15, bull.

Figs 12, 14 and 16. Sections of chemically fixed spermatozoa. Fig. 12, boar; Figs 14 and 16, bull. 
PLATE I
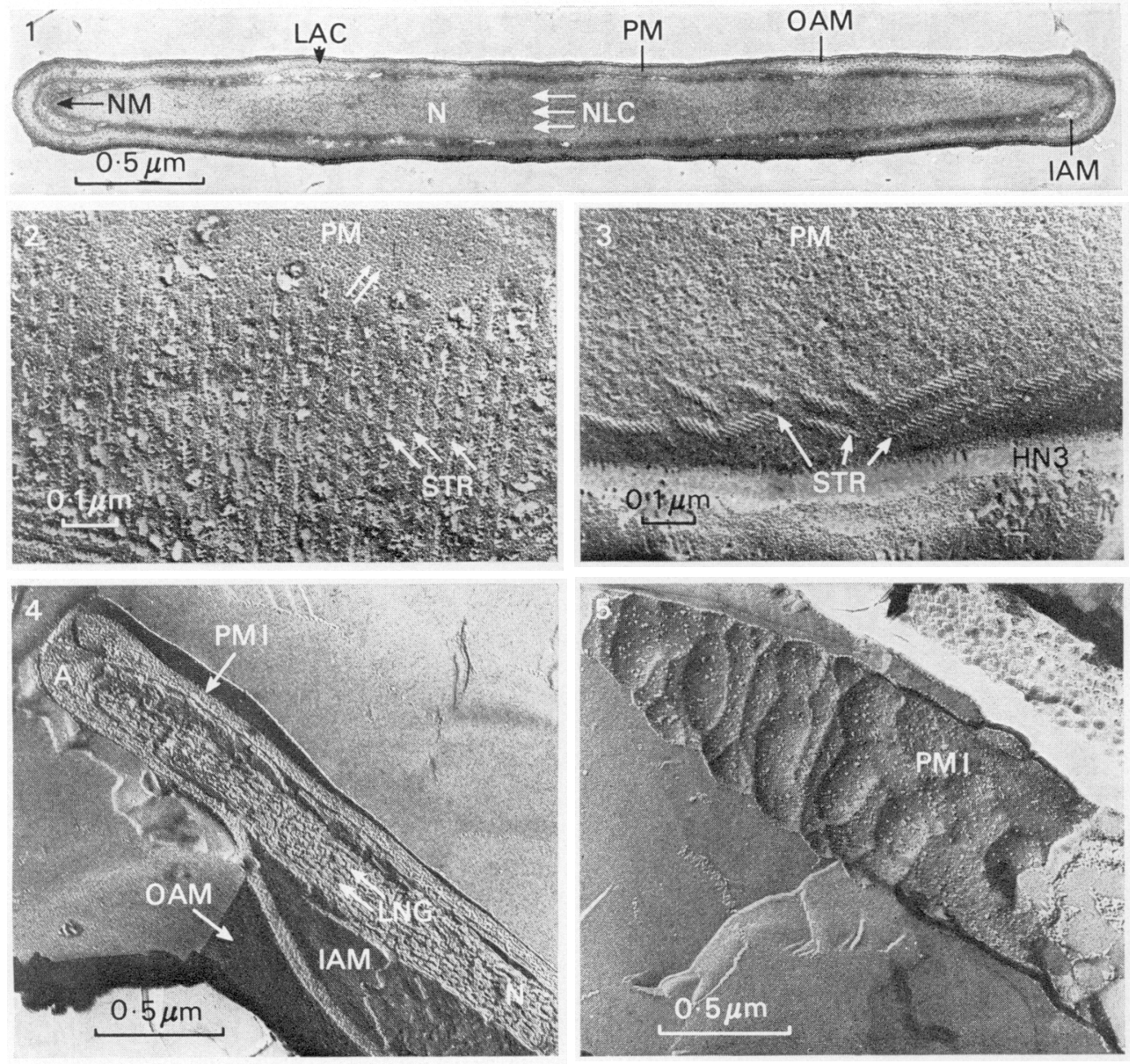
PLATE 2
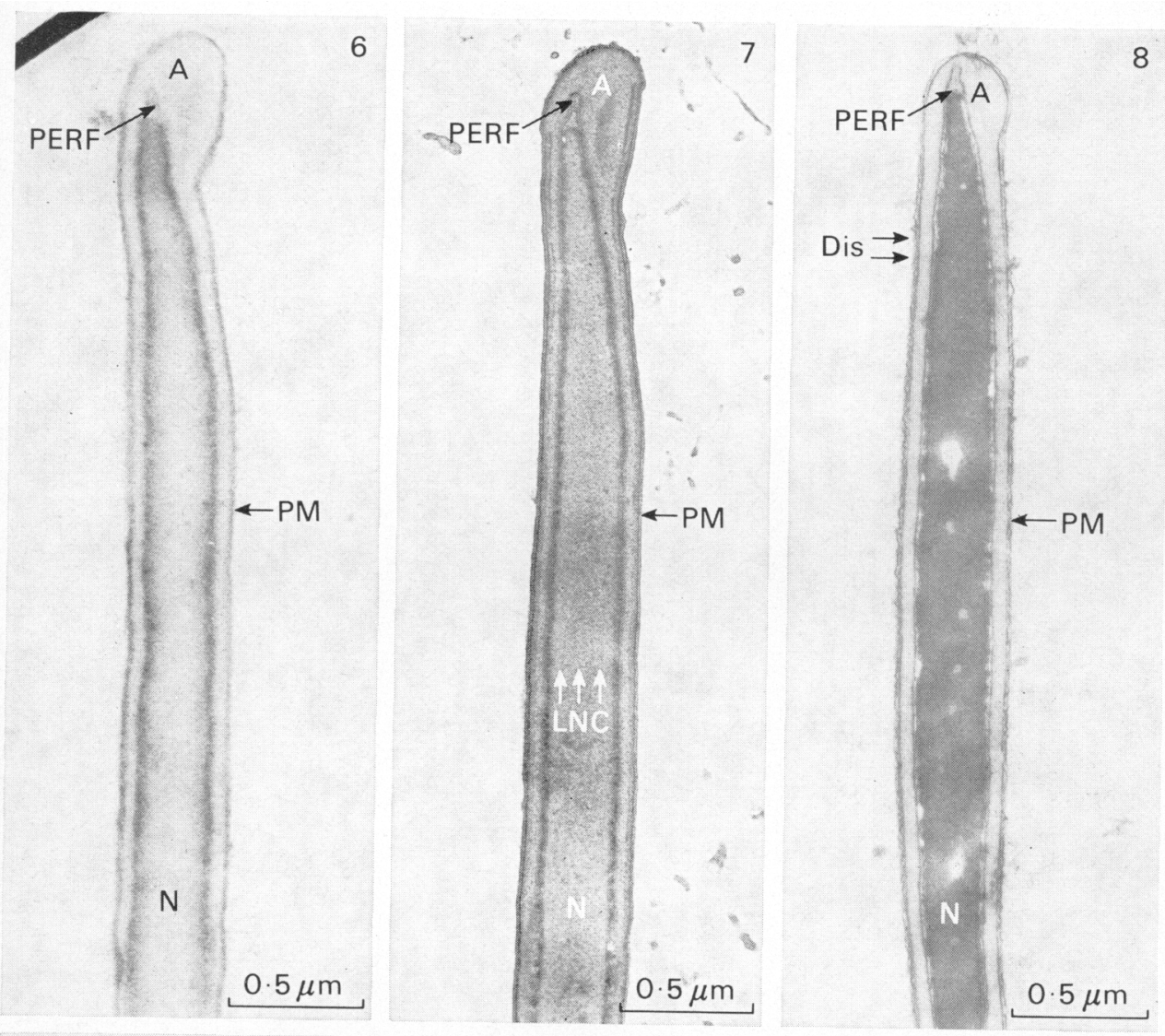

9
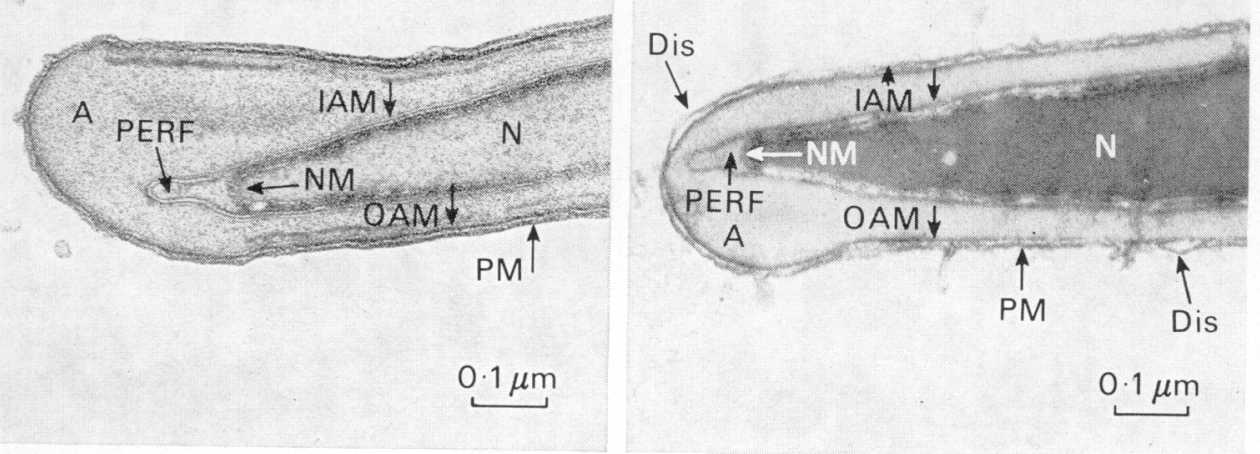
PLATE 3

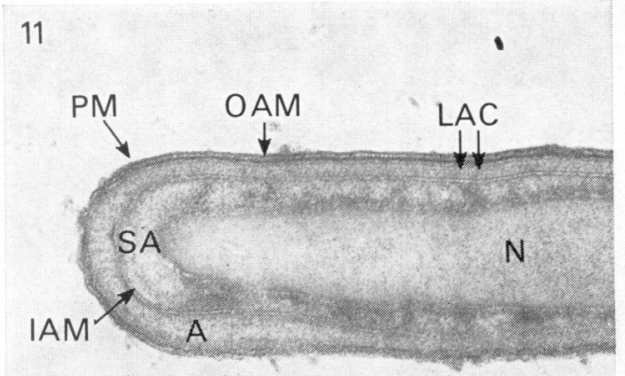

$0.1 \mu \mathrm{m}$

13

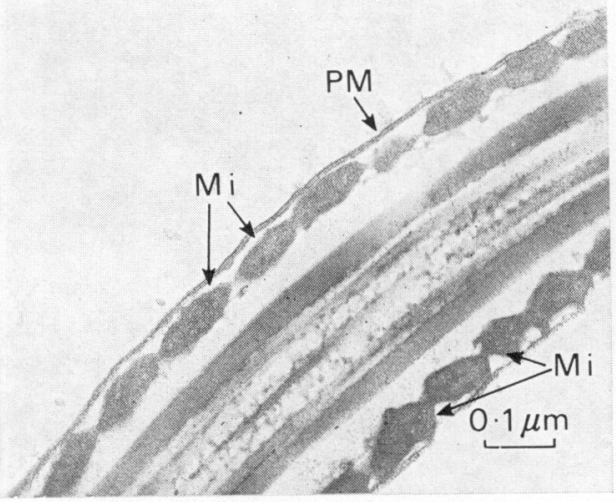

15

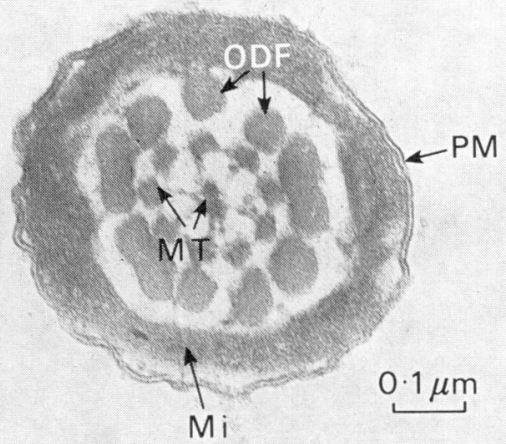

12
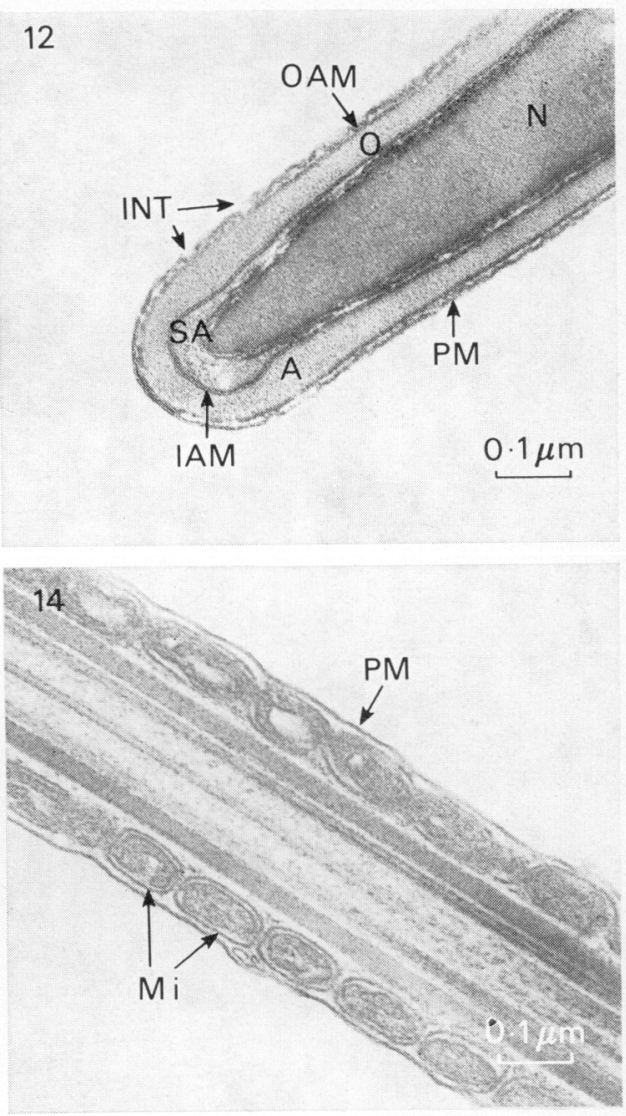

16

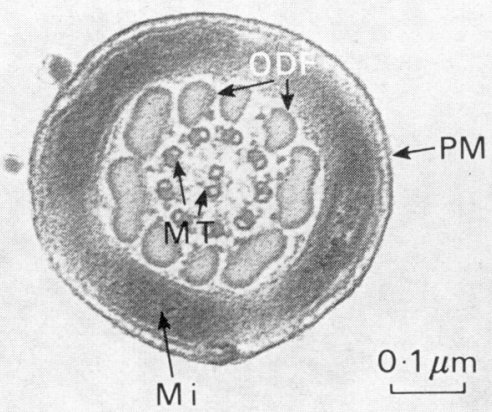




\section{Discussion}

The results obtained substantiate earlier studies (Plattner, 1971; Plattner, Fischer, Schmitt \& Bachmann, 1972) in which the structural preservation of spray-frozen and freeze-etched cells were compared with the preservation of chemically fixed cells. However, the freeze-fracture replicas provide only morphological information and preclude further treatment to obtain additional information about the cellular components, while chemical fixation and resin-embedding permit additional processing steps, as for histochemical analyses.

This investigation was performed to combine the advantage of spray-freezing as an optimal method of cryofixation for unicellular objects with the possibility of additional histochemical investigations permitted by thin sectioning. The most suitable way of attaining this combination was found to be freeze-drying and embedding of spray-frozen spermatozoa. Freeze-substitution fixation as another preparation step applicable after cryofixation (Rebhun, 1961; Van Haareveld \& Fifkova, 1975) does not eliminate the problems inherent with chemical fixation, such as protein denaturation, extraction of lipids, and alteration of cellular materials. Ultracryotomy of spray-frozen material would be an alternative method, but only one study, on spermatozoa of Hydaticus transversalis, has been reported (Werner, Morgenstern \& Neumann, 1972).

The technical and physical factors which may influence the drying procedure used in the present investigation are largely discussed in the papers of Williams (1954), Merryman (1966) and Bullivant (1970). As shown in the present study freeze-drying does not affect the structural preservation of spermatozoa which is as good as that provided by cryofixation. However, there are some effects which we cannot explain, e.g. the relatively high electron contrast of freeze-dried, unosmicated and unstained specimens. The freeze-drying and vacuum-embedding technique did reveal some features that have not been described previously, e.g. fine lamellar structures within the bull acrosome, but the preservation of the flagellar complex was not as good as that of the sperm head when compared to chemical fixation, perhaps because of a higher water content or resistance to resin infiltration.

Differences in the state of hydration in the middle piece may also be involved, and it should be remembered that in freeze-etching studies it is not possible to obtain specimens demonstrating middlepiece structures comparable to those of chemical fixation, regardless of whether the spermatozoa are spray-frozen or frozen after treatment with antifreeze.

However, we believe that the freeze-drying and vacuum-embedding method described here for spray-frozen spermatozoa offers a way of preserving the ultrastructure of these cells as close as possible to that of the living material, and additionally provides a suitable basis for further histochemical investigations which have been restricted to those not influenced by fixatives and dehydration media.

The investigation was supported by Grants No. 1835 and 2183/N39 of the Österreichischer Fonds zur Förderung der wissenschaftlichen Forschung. We thank Miss Brigitte Pistiner for her skilful technical assistance and Dr H. Plattner, Institute of Biochemistry and Experimental Cancer Research, University of Innsbruck, Austria, for discussing the experimental findings and their interpretation.

\section{References}

BACHMANN, L. \& SchmitT, W.W. (1971) Improved cryofixation applicable to freeze etching. Proc. natn. Acad. Sci. U.S.A. 68, 2149-2153.

Blom, E. \& Birch-Anderson, A. (1960) The ultrastructure of the bull sperm. I. The middle piece. Nord. VetMed. 12, 261-279.

Blom, E. \& Birch-ANDerson, A. (1965) The ultrastructure of the bull sperm. II. The sperm head. Nord. VetMed. 17, 193-212.

Bullivant, S. (1970) Present status of freezing technique.
In Some Biological Techniques in Electron Microscopy, pp. 101-146. Ed. D.F. Parsons. Academic Press, New York.

FAWCETT, D.W. (1970) A comparative view of sperm ultrastructure. Biol. Reprod., Suppl. 2, 90-127.

Gersh, I. \& Stephenson, J.L. (1954) Freezing and drying of tissues for morphological and histochemical studies. In Biological Applications of Freezing and Drying, pp. 329-363. Ed. R.J.C. Harris. Academic Press, New York. 
Gersh, I., Veraga, J. \& Rossi, G.L. (1960) Use of anhydrous vapours in postfixation and in staining of reactive groups of proteins in frozen dried specimens for electron microscopic studies. Anat. Rec. 138, 445-453.

HANCOCK, J.L. (1966) The ultrastructure of mammalian spermatozoa. Adv. Reprod. Physiol. 1, 125-145.

HANZON, V. \& HeRModson, L.H. (1960) Freeze drying of tissue for light and electron microscopy. J. Ultrastruct. Res. 4, 332-348.

JoNEs, R.C. (1970) Ultrastructure of mammalian spermatozoa: the effect of buffer concentration in fixatives for boar spermatozoa. Micron 2, 350-362.

KOEHLER, J.K. (1965) Fine structure observations in frozen etched bovine spermatozoa. J. Ultrastruct. Res. 16, 359-375.

KOEHLER, J.K. (1970) A freeze-etching study of rabbit spermatozoa with particular reference to head structures. J. Ultrastruct. Res. 33, 598-614.

MerRYMaN, H.T. (1966) Freeze-drying. In Cryobiology, pp. 610-663. Ed. H.T. Merryman. Academic Press, New York.

MüLLER, H.R. (1957) Gefriertrocknung als Fixiermethode an Pflanzenzellen. J. Ultrastruct. Res. 1, 109-137.

NICANDER, L. \& BANE, A. (1966) Fine structure of sperm head with particular reference to the acrosome and subacrosomal substance. Z. Zellforsch. mikrosk. Anat. 57, 390-405.

PlatTNer, H. (1971) Bull spermatozoa: a reinvestigation by freeze etching using widely different cryofixation procedures. J. Submicrosc. Cytol. 3, 19-32.

Plattner, H., Fischer, W.M., Schmit, W.W. \& BaChMaNN, L. (1972) Freeze-etching without cryoprotectants. J. Cell Biol. 53, 116-126.
Plattner, H., Schmitt-Fumlan, W.W. \& BachmanN, L. (1973) Cryofixation of single cells by spray freezing. In Freeze-etching, Technique and Application, pp. 81-100. Eds E.L. Benedetti \& R. Faward. Soc. Fr. Micr. Electr., Paris.

REBHUN, L.J. (1961) Application of freeze substitution to electron microscope studies of invertebrate oocytes. Biophys. Biochem. Cytol. 9, 785-789.

REYNOLDS, E.S. (1963) The use of lead-citrate at high $\mathrm{pH}$ as an electron-opaque stain for electron microscopy. J. Cell Biol. 17, 208-212.

SAACKE, R.G. \& ALMQUIST, J.O. (1964a) Ultrastructure of bovine spermatozoa. I. The head of normal ejaculated sperm. Am. J. Anat. 115, 143-162.

SAACKE, R.G. \& ALMQUIST, J.O. (1964b) Ultrastructure of bovine spermatozoa. II. The neck and tail of normal ejaculated sperm. Am. J. Anat. 115, 163184.

Suöstrand, F.S. \& Baker, R.F. (1958) Fixation by freeze drying for electron microscopy of tissue cells. J. Ultrastruct. Res. 1, 239-246.

StiRLING, C.E. \& KINTER, W.B. (1967) High resolution autoradiography of galactose- ${ }^{3} \mathrm{H}$-accumulation in rings of hamster intestine. J. Cell Biol. 35, 585-604.

Van HaAReVeld, A. \& Fifkova, E. (1975) Rapid freezing of deep cerebral structures for electron microscopy. Anat. Rec. 182, 377-385.

Werner, G., Morgenstern, E. \& NeumanN, K. (1972) Uitradünne Gefrierschnitte von unfixierten, nicht eingebetteten biologischen Objekten. III. Spermien. Mikroskopie 28, 80-87.

WiLliams, R.C. (1954) The application of freeze-drying to electron microscopy. In Biological Applications of Freezing and Drying, pp. 303-398. Ed. R.C.M. Harris. Academic Press, New York. 